\title{
Aportes de la geografía y la arqueología para el análisis de las transformaciones en el humedal de lagunas del noreste mendocino
}

\author{
Prof. Fernando Hernández \\ Profesor de Geografía, FFyL, UNCuyo. \\ CIRSF \\ Municipalidad de Mendoza. \\ E-mail: josefernah@gmail.com \\ Lic. Horacio Chiavazza \\ Dr. en Arqueología, FFyL UNCuyo. Dir. \\ Área Fundacional, \\ Municipalidad de Mendoza.
}

\begin{abstract}
Resumen
Trabajando desde un enfoque interdisciplinario se presentan los resultados obtenidos con el análisis de procesos de fluctuación ambiental, concretamente humedales del norte de Mendoza, durante los últimos (circa) 200 años. Complementando informaciones procedentes de imágenes de satélite y documentación cartográfica histórica, se chequean hipótesis referidas al proceso de variaciones en la disponibilidad de agua y sus vínculos con los procesos de poblamiento regional.
\end{abstract}

Palabras clave: Humedales. SIG. Geaorquelogía.

\section{Summary}

Working from an interdisciplinary approach to present the results of the analysis processes of environmental fluctuation, including wetlands of northern Mendoza, over the past (circa) 200 years. Complementing information from satellite imagery and mapping historical documentation is checked assumptions concerning the process of changes in water availability and its links with the processes of regional settlement.

Key words: Wetlands. GIS. Geoarchaeology. 


\section{INTRODUCCIÓN}

Se presentan los resultados de las tareas realizadas como parte de un proyecto marco de la SECTyP, UNCuyo, 2007-2009 denominado "Ambiente, cultura y relaciones interétnicas en el área huarpe del NE de Mendoza durante el siglo XVIII. Continuidades y transformaciones que contribuyeron a los procesos de articulación social" (Chiavazza y Prieto 2009).

El área de interés quedó definida por una franja que en forma de arco con sentido NW - SE es adyacente al río Desaguadero y reconoce como límites el complejo de lagunas de Guanacache y el río San Juan hacia el norte, el cauce del río Mendoza hacia el oeste y el río Tunuyán hacia el sur.

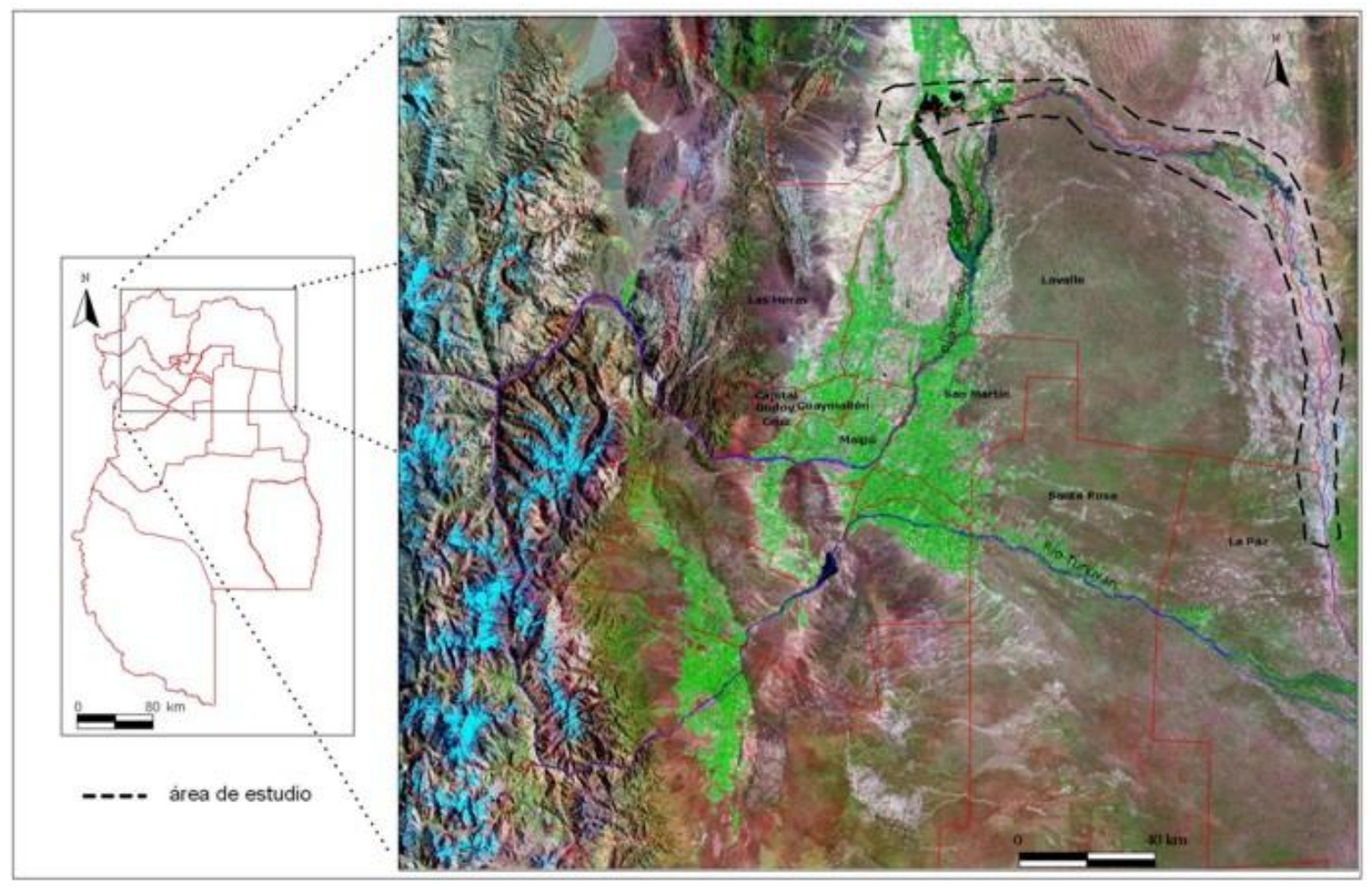

Figura 1. Área de estudio.

Las tareas interdisciplinarias estuvieron orientadas a:

1) Recopilar imágenes satelitales de diferentes momentos temporales (años) y estacionales (verano - otoño)

2) Trasladar datos e información histórica a una imagen satelital georeferenciada del área de estudio, analizada a distintas escalas.

3) Elaborar interpretaciones acerca de la relación dada entre el ambiente y los grupos humanos a través de estudios de sitios arqueológicos detectados en las prospecciones. 
El trabajo se caracterizó por su cualidad técnica al trabajar con imágenes satelitales y Sistemas de Información Geográfica, herramientas que se vinculan con el desarrollo tecnológico, y sobre todo informático de las últimas décadas. Esto nos permitió utilizar software de análisis e interpretación para identificar, a través de las mismas, aspectos naturales y culturales del territorio e integrarlos destacando las interacciones a partir de los datos existentes en documentos históricos. Del mismo modo, la utilización de un Sistema de Información Geográfica nos permitió integrar todo este conjunto de datos y establecer relaciones entre los mismos (Bosque Sendra 1992, Buzai 2005, Capel 1998 Ceballos García, B. 2002).

Nuestro postulado sostiene que la integración de imágenes satelitales, correspondientes a distintos períodos y estaciones del año con la información obtenida de documentos históricos permite reconocer áreas probables de ocupación humana reflejando la relación entre las poblaciones y el entorno natural y sus procesos de transformación.

\section{MARCO Y CATEGORÍAS CONCEPTUALES}

Los fenómenos que se manifiestan en el ambiente son consecuencia de la interacción de variados elementos; por lo tanto el análisis de los fenómenos espaciales debe ser abordados incorporando diferentes miradas que permitan integrar en una explicación inclusiva, de los roles que cumplen los elementos y que hacen a la totalidad del fenómeno. Esta interdisciplinariedad permite comprender procesos que analizados desde enfoques parcelarios pasarían inadvertidos (Barros y Nastri 1995, Matteucci y Scheinsohn. 2004).

La capacidad de identificar en el análisis los diferentes elementos que actúan y definen un fenómeno territorial es concebir la realidad como una "...totalidad constituida por partes interconexas entre si" (Vagaggini y Dematteis, 1977).

En estas partes que interactúan se incluye al grupo humano, que como sociedad, es decir como grupo organizado, toma decisiones sobre el ambiente y por lo tanto produce el territorio que ocupa. Lo produce a través de las transformaciones que realiza o, simplemente, a través de las formas de uso del espacio la forma de transitarlo, e incluso también desde la forma de concebirlo desde su esfera de creencias. De este modo, estas transformaciones se amalgaman componiendo un paisaje que identifica al territorio ocupado por una sociedad. En términos de Criado Boado, este paisaje se presenta como: "...un producto socio-cultural creado por la objetivación, sobre el medio y en términos espaciales, de la acción social tanto de carácter material como imaginario." (Criado Boado, 1999:8).

Incorporar en nuestro trabajo el concepto de "Humedal" nos permitió definir tres áreas consideradas claves a nuestros objetivos. El concepto de humedal posee un doble significado. Tradicionalmente se lo identifica con zonas planas donde la capa freática se localiza cerca de la superficie por lo cual se cubre de agua en forma permanente o intermitente, saturando el suelo, dejándolo sin oxígeno y generando un ecosistema híbrido entre los ecosistemas acuáticos y terrestres. Este concepto 
fue revisado a comienzos de la década de 1970, a partir de la "Convención Relativa a los Humedales de Importancia Internacional especialmente como Hábitat de Aves Acuáticas", conocida como Convención Ramsar, en la cual se amplió el concepto de humedal, rescatando su importancia para el conjunto de seres vivos que lo ocupa. De este modo, el Humedal es:

“...una zona de la superficie terrestre que está temporal ó permanentemente inundada, regulada por factores climáticos y en constante interrelación con los seres vivos que la habitan (...) las extensiones de marismas, pantanos y turberas, o superficies cubiertas de aguas, sean éstas de régimen natural $o$ artificial, permanentes o temporales, estancadas o corrientes, dulces, salobres o saladas, incluidas las extensiones de agua marina cuya profundidad en marea baja no exceda de seis metros".(Documento Informativo Ramsar № 1, 1998: 1).

Como importancia esencial de los humedales la Convención Ramsar define:

"Los humedales figuran entre los ecosistemas más productivos de la tierra y son fuentes de diversidad biológica, pues aportan el agua y la productividad primaria de la que innumerables especies vegetales y animales dependen para su supervivencia. Sustentan elevadas concentraciones de aves, mamíferos, reptiles, anfibios, peces y especies invertebradas. De las 20.000 especies de peces que hay en el mundo, más del 40 por ciento vive en aguas dulces. Los humedales son asimismo importantes lugares de almacenamiento de material genético vegetal". (Documento Informativo Ramsar № 1, 1998: 2).

La República Argentina aprobó la Convención Ramsar y la firmó como país integrante en el año 1991, desde entonces a través de la Dirección General de Asuntos Ambientales, declaró seis grandes regiones de humedal en los cuales se realizan los estudios pertinentes para conocer su situación, posibilidades de manejo, etc.

Diversos autores interesados en el sector de la llanura noreste de Mendoza han incorporado el concepto de humedal en sus investigaciones destacando el rol que jugó y juega como sostén esencial para la vida en la región (Prieto 2000, Sosa et al 1998, Chiavazza 2001, entre otros).

Si bien se identifica como Humedal de Guanacache a todo el sistema lacunar ubicado en el límite entre las provincias de Mendoza, San Juan y San Luis (Sosa et al 1998) formado por lagunas menores, bañados y áreas inundadas por los ríos Mendoza y San Juan, a los fines prácticos, en nuestro trabajo elaboramos una subdivisión en tres ambientes que reconocemos a partir de una carta histórica del año 1789, y son hoy catalogados como ambientes de humedal (con mayor o menor desarrollo e impacto):

1- Humedal de lagunas de Guanacache: El de mayor relevancia por su valor histórico, arqueológico y cultural para las comunidades humanas locales. Ubicado en el norte de la provincia de Mendoza es alimentado por las aguas del 
río Mendoza antes de cambiar su curso hacia el este y está compuesto por un extenso complejo de lagunas.

2- Humedal de lagunas de San Miguel: Importante también por su valor histórico y cultural, al igual que el humedal de lagunas de Guanacache es un importante polo de asentamiento de comunidades Huarpes. Compuesto principalmente por bañados y áreas inundadas, se forma a partir de las aguas del río Mendoza cuando cambia su curso hacia el este.

3- Humedal de lagunas al sur de San Miguel (sector de Arroyito): Al igual que los anteriores, importante polo de asentamiento humano. Ubicado en el límite entre la provincia de Mendoza y San Luis, formado por lagunas menores como la de las Quijadas, la de Silverio, la de los Chomes, la del Salto, entre otras (Prieto 1982, Chiavazza y Prieto 2009).

En la figura 2 se observa la carta histórica y la imagen satelital correspondiente al norte de Mendoza. En la misma se señalan en color rojo los ambientes mencionados, en ambos casos georeferenciados. 


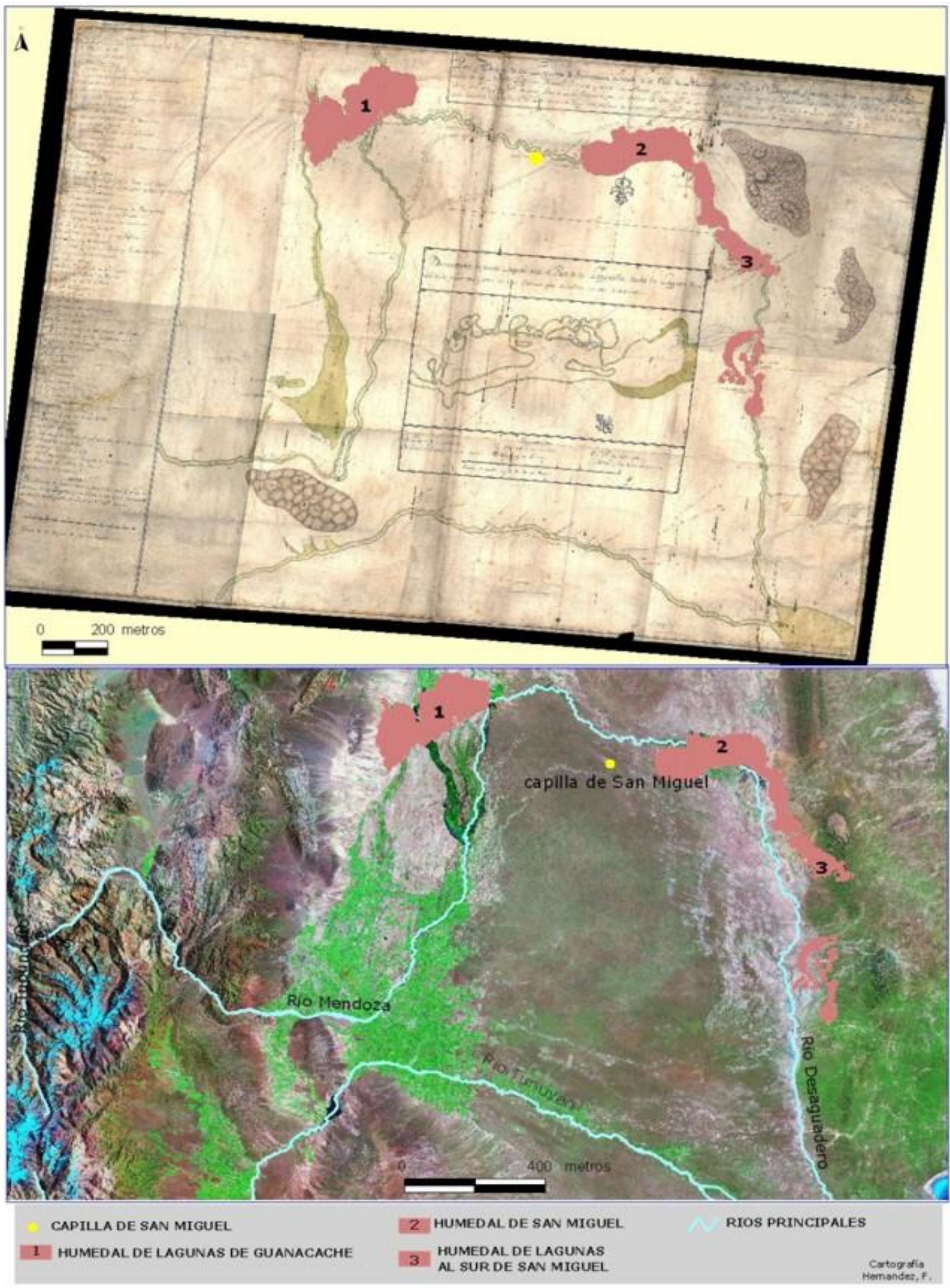

Figura 2. Mapa histórico e imagen satelital con subdivisión de humedales 


\section{MATERIALES Y MÉTODOS}

En esta segunda etapa del proyecto continuamos trabajando con un documento histórico clave para nuestra investigación: el documento de viaje y mapa elaborado por Ximenez Inguanzo en el año 1789, utilizado en varios trabajos de Historia y Arqueología de la región con diversos objetivos (Abraham y Prieto 1981, Chiavazza 2007, Chiavazza et al 2002, Vignati 1953).

Las cualidades de este documento para la visualización de los aspectos culturales y naturales del territorio en la segunda mitad del siglo XVIII han sido mencionadas en diferentes trabajos (Abraham y Prieto 1981; Chiavazza 2001, Chiavazza et al 2002). Justamente a partir de las mismas se procedió a chequear la verosimilitud de su escala y mención a lugares que permitieran emprender trabajos arqueológicos ambientales (Chiavazza 2007). Así, un primer trabajo vinculado con el presente (Hernández y Chiavazza 2008) apuntó a precisar escalas espaciales entre aquel documento e imágenes satelitales, las que fueron utilizadas en proyectos de localización y análisis arqueológicos ambientales del sector del río Desaguadero con resultados altamente satisfactorios (Chiavazza y Prieto 2009).

Para cumplir con el primer objetivo propuesto, recurrimos a la obtención de imágenes a través del sitio web Global Land Cover Facility, de la página de la Universidad de Maryland, EEUU, que autoriza la descarga de archivos de imagen satelital de distintos formatos con bandas incluidas, lo que nos permite componer la imagen de acuerdo a nuestras necesidades.

En este sentido, trabajamos sobre la carta histórica de primavera de 1789 a la que superpusimos las siguientes imágenes:

- imagen satelital de 1989 (verano)

- imagen satelital de 2001 (otoño)

- imagen satelital de 2006 (otoño)

Estas se trabajaron con el software denominado ENVI 3.5 software informático que permite visualizar las imágenes LANDSAT por bandas y realizar composiciones de imágenes combinando diferentes bandas.

La composición de imágenes resulta significativa para nuestro proyecto debido a que, según la combinación establecida, se reflejan diferentes aspectos del territorio. En este sentido, el trabajo cartográfico requiere de decisiones acordes a los intereses del proyecto, por lo que se decidió trabajar con la combinación banda 7/4/2 por su característica de resaltar aspectos referidos a la vegetación y la humedad del terreno.

Respecto al segundo objetivo propuesto, utilizamos el software ARC VIEW 3.2 para la digitalización de los aspectos culturales y naturales representados en la carta histórica de 1789. Esto nos permitió otorgarles el formato de shapes o cobertura temática e independizarlos de la imagen histórica para integrarlos con su 
correspondiente referencia espacial a las imágenes satelitales y establecer comparaciones.

Mediante el software Global Mapper versión 7.0 que permite la visualización de los distintos formatos, trabajamos las imágenes obtenidas y la carta histórica, con el fin de realizar mediciones y de este modo identificar las variaciones entre los diferentes períodos.

\section{RESULTADOS}

Las características naturales y culturales que presenta la llanura del este mendocino han sido analizadas por numerosos autores (Chiavazza 2001, González Díaz y Fauqué, 1993, Prieto, et al 1995, Prieto y Chiavazza 2006, Regairaz y Barrera 1975; Rusconi 1962, etc.) entre ellas ponemos énfasis en el importante rol que juegan los cursos de agua, dado el alto índice de aridez existente en la región. Estos cursos de agua actualmente no transportan grandes caudales hacia la llanura, incluso, el caso del río Mendoza es que durante largas temporadas permanece seco. Trasladar esta situación al análisis del poblamiento en el pasado podría dar lugar a equívocos. Las causas antrópicas de este proceso se reconocen en el uso que se realiza en el oasis irrigado de las aguas de los ríos cordilleranos, tanto para el consumo urbano como para riego en la periferia urbana. Sin embargo, históricamente lo hicieron y generaron un extenso sistema hidrográfico permanente, integrado al denominado sistema del Colorado-Chadileuvú, que posibilitó la ocupación humana del sector de llanura, a pesar de sus condiciones de marcada aridez.

Las tareas de investigación arqueológica de campo desarrolladas a partir de la orientación generada por el análisis de imágenes satelitales (Chiavazza, 2001, 2007) han permitido proponer que la ocupación humana del sector de los humedales se presentó de modo intenso y permanente desde hace 1.600 años antes del presente. Sin embargo esto podría retrotraerse a etapas de unos 4.000 a 5.000 años más antiguas en el contexto regional más amplio del noreste, cuando experimentó cambios de curso de ríos y desarrollos de humedales en sectores que actualmente carecen totalmente de agua (Sitio Los Ponce PA46, Chiavazza 2007).

En el presente, la densidad de población ha disminuido notablemente. Las causas de este proceso son analizadas en detalle en otros trabajos (Cfr. Abraham y Prieto 1981, Prieto, M.R. 1982). Coincidimos con la idea de que como causa antrópica principal a esta disminución en la densidad de habitantes se presenta un marcado y sostenido proceso de desarraigo y abandono, iniciado con la incorporación a la encomienda en etapas coloniales (Chiavazza y Prieto 2009, Rusconi 1962) y con el proceso de proletarización rural al que fueron conducidos sus habitantes durante el período de consolidación del Estado Argentino, iniciado el siglo XIX. El marco ambiental de este proceso estuvo dado por la sostenida ampliación de los sistemas de regadío en el oasis, lo que actuó en desmedro del desarrollo de los humedales del norte. 
Esta condición de abandono y marginalidad que caracteriza a las poblaciones de la llanura del noreste mendocino, es posible observarla actualmente a través de la oferta de servicios que el Estado ofrece en el área, nos referimos a escuelas, centros de salud, establecimientos policiales, vías de comunicación, etc. La notable ausencia de estos servicios básicos, han condenando a sus habitantes aún más a una situación de marginalidad. En la figura 3 puede observarse el sector noreste de la provincia como un sector aislado, marginal y prácticamente carente de servicios, consecuencia del escaso interés productivo del área durante los sucesivos gobiernos del siglo XX (Abraham y Prieto, 1981). Incluso, al recorrer los puestos de la zona, es fácil observar el mantenimiento de una economía pastoril tradicional, centrada en la provisión de agua procedente de "pozos balde" (Triviño 1977).

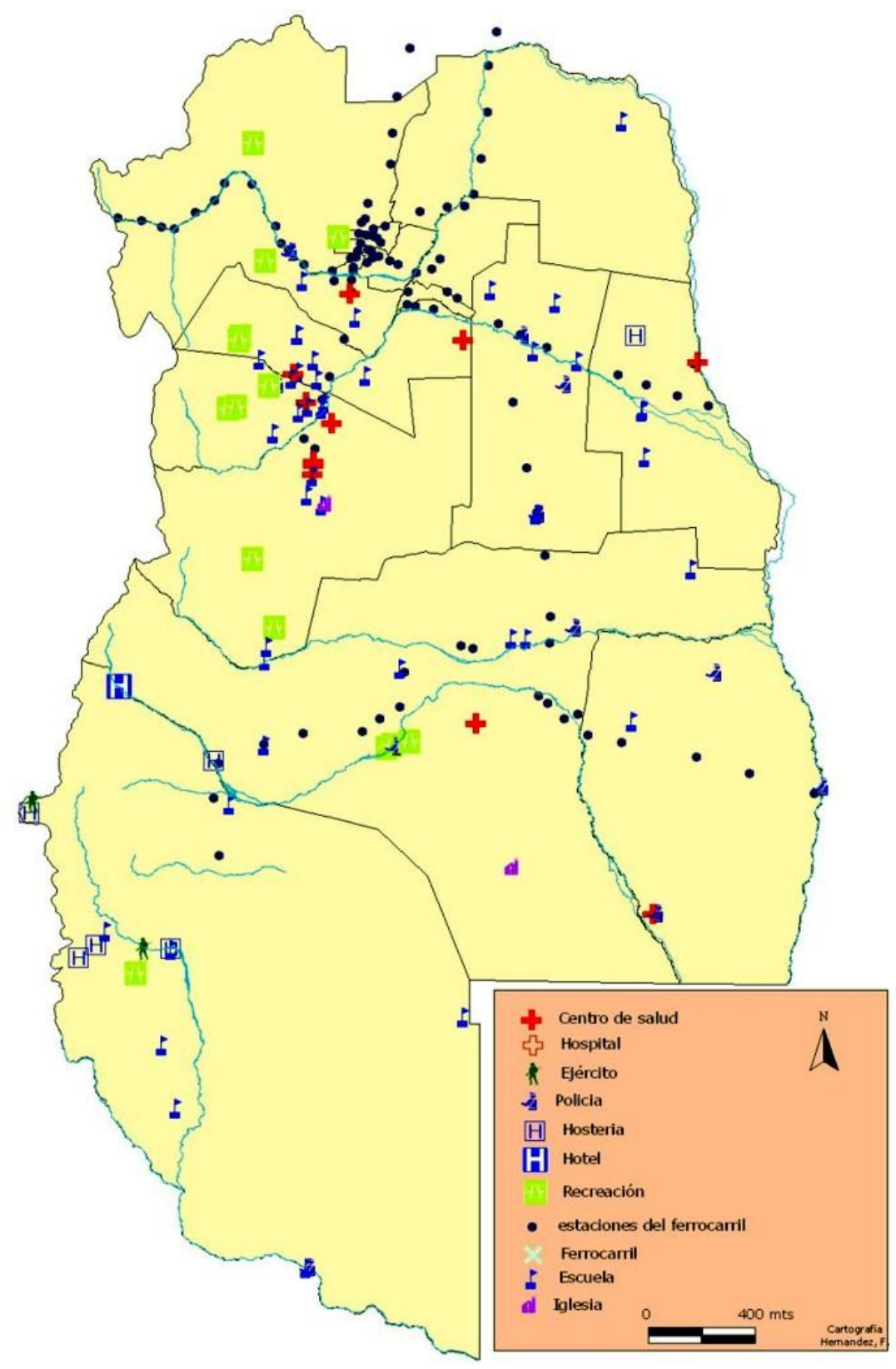

Figura 3. Localización a nivel provincial de servicios del Estado 
El recurso agua se presenta como vital para la subsistencia de las poblaciones en la región. Las variaciones en la disponibilidad de este recurso fueron ya tratadas así como sus consecuencias en diferentes trabajos (Abraham y Prieto, 1981, Chiavazza 2001, Chiavazza y Prieto 2009, Hernández y Chiavazza, 2008, Prieto et al 1995, Prieto y Chiavazza 2006).

La distribución de los espejos y cauces de agua es uno de los aspectos naturales observado y relevado en el documento histórico de 1789. En la figura 4 observamos esta distribución, distinguiendo entre cauces permanentes y espejos de agua como lagunas o bañados.

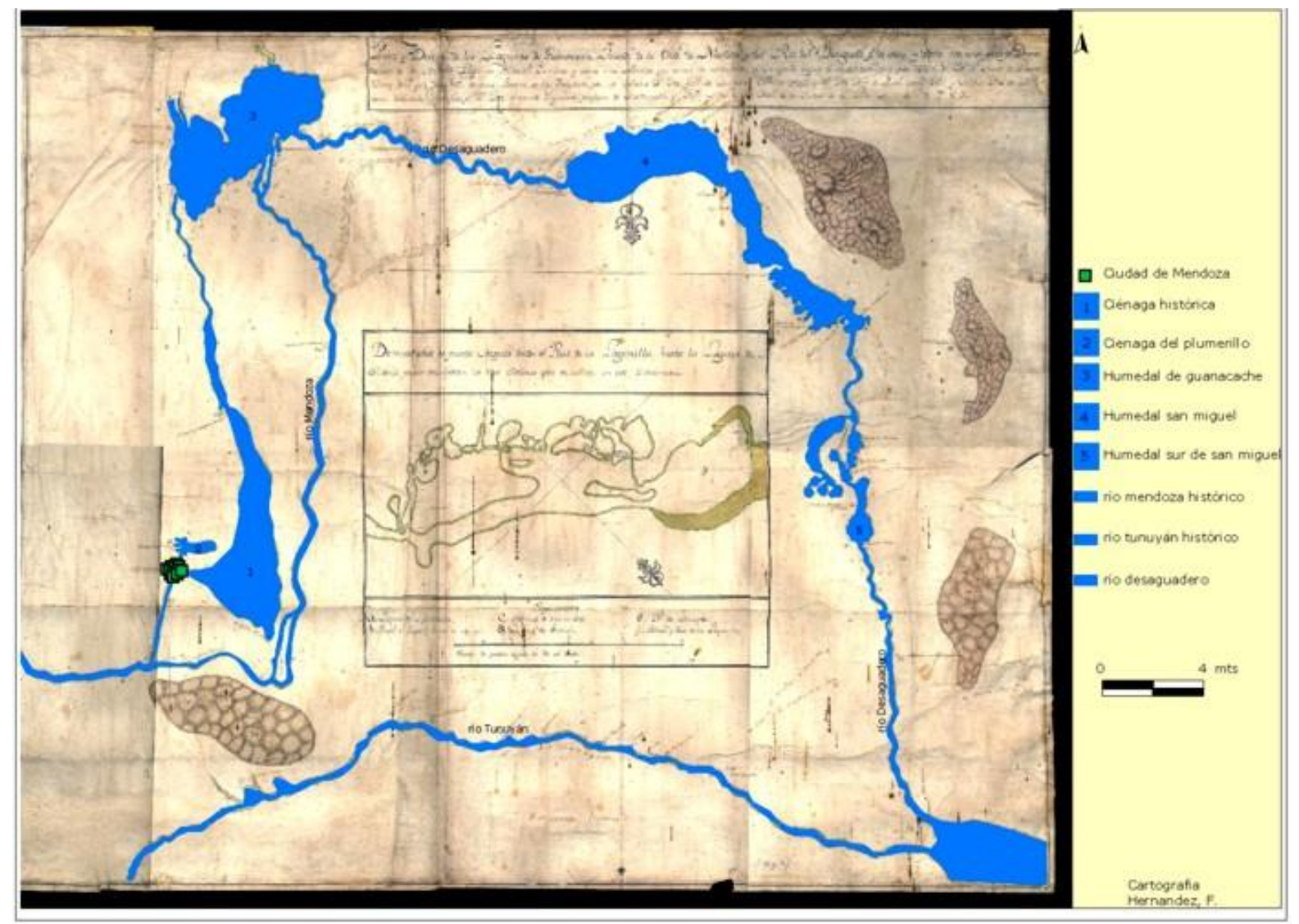

Figura 4. Distribución de cauces y espejos de agua en carta de 1789.

A partir de las imágenes correspondientes a diferentes momentos temporales elaboramos un cuadro comparando las extensiones aproximadas ocupadas por las áreas de humedal (tabla 1). Esta secuencia de imágenes nos permite comparar el comportamiento de estos humedales en los últimos 217 años, reflejando en general, una marcada regresión de los mismos. 


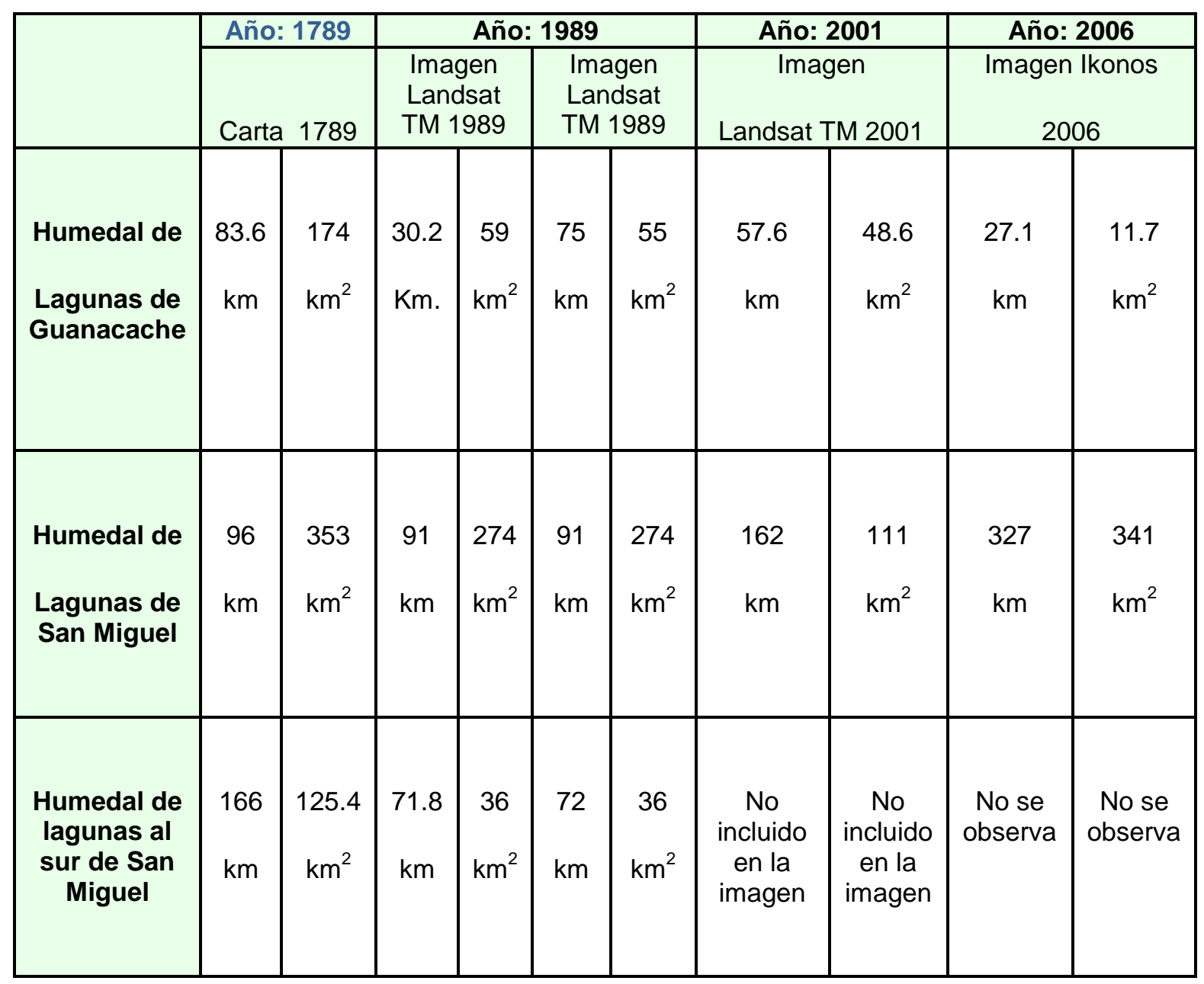

Tabla 1. Comparación de extensiones aproximadas de áreas ocupadas por humedales en diferentes momentos temporales 
Se destaca el humedal de lagunas de Guanacache como el que sufrió una mayor retracción respecto del área ocupada según el registro del año 1789 (figura 5).

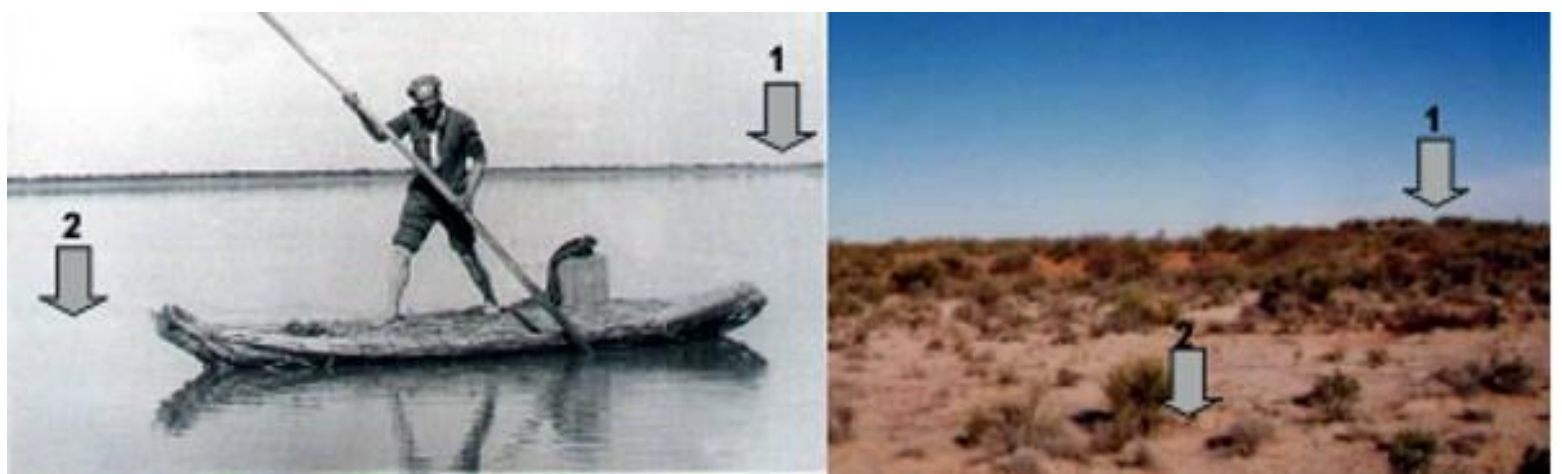

Figura 5. Dos fotografías del ambiente de lagunas de Guanacache-Rosario: Izq. 1939: laguna de la Balsita (a pleno). Der. 1996. Laguna del Rosario (seca) (Chiavazza 2001, Roig et al 1999). 1. Bordos, 2. Laguna izq y fondo de laguna der.

El de San Miguel se presenta como el humedal con menores variaciones ya que de acuerdo a las imágenes del año 2006, se observa un crecimiento en la extensión del área ocupada por el mismo. Aunque disminuido en comparación con lo graficado en 1789.

El humedal de lagunas al sur de San Miguel (Arroyito) es el que mayores variaciones experimentó, a tal punto que no se observan lagunas ni bañados, detectándose un proceso de desecación intenso. De todos modos, sabemos por informantes locales que en ciertas temporadas experimentó un crecimiento considerable a partir de los desbordes del río Desaguadero. En 2005 prospectamos la zona y pudimos observar un notable crecimiento entre agosto y diciembre (figura 6).
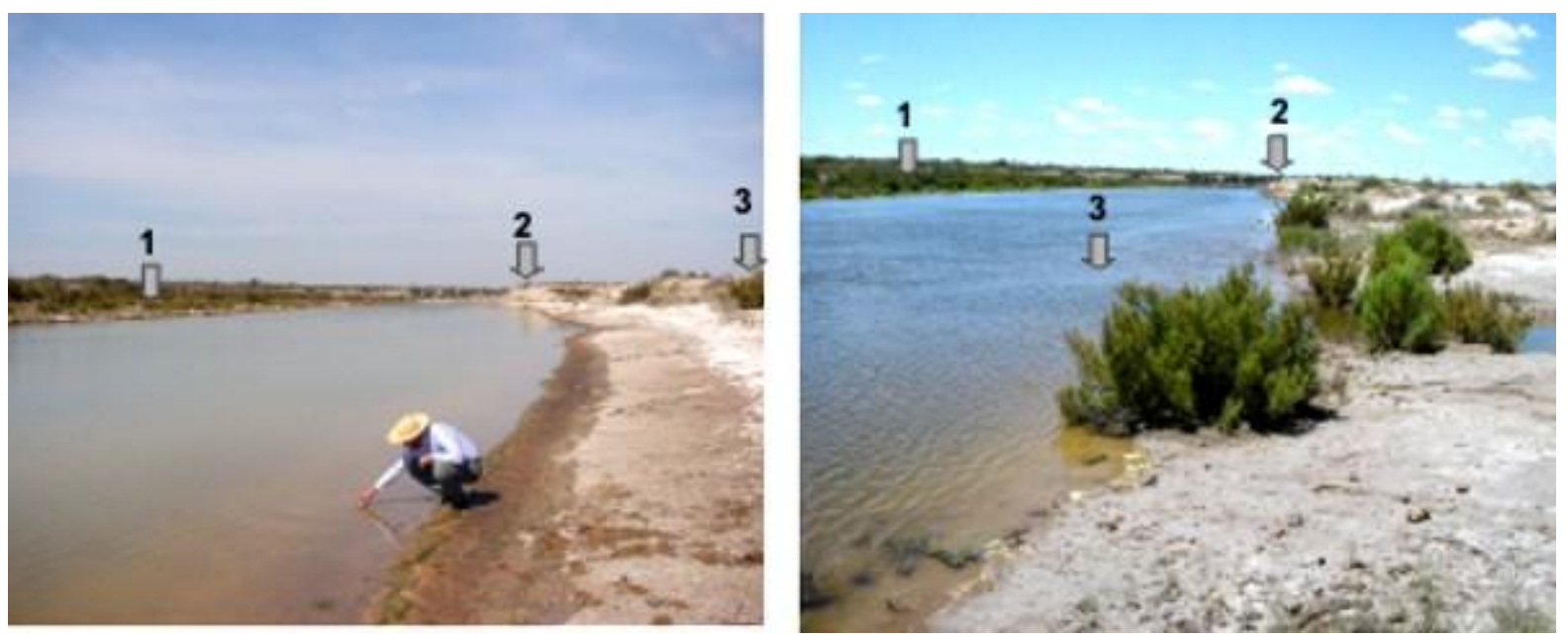

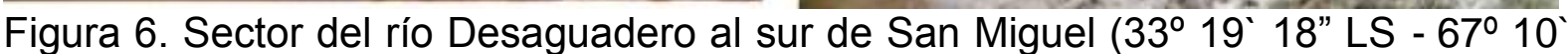
4.1" LW ) en setiembre (izq) y diciembre del año 2005: 1. margen este, 2. margen oeste, 3 margen oeste) en los tres puntos se nota el claro ascenso del nivel del río y desborde, que estimamos en unos dos metros (Chiavazza y Prieto 2009). 
En la figura 7 se observa en detalle la regresión del Humedal de San Miguel. La comparación se realiza sobre las imágenes correspondientes a los años 1989, 2001 y 2006. La imagen correspondiente al año 1989 responde a una situación excepcional por tratarse del año posterior al año niño húmedo, con crecidas importantes de los ríos Mendoza y San Juan. El fenómeno Niño húmedo ocasiona grandes nevadas en la Cordillera de los Andes en período invernal y abundantes precipitaciones en el llano en período estival. Diferentes autores han trabajado sobre las consecuencias de este fenómeno, para Mendoza, nos interesa destacar el trabajo realizado por Prieto, Herrera y Dussel, acerca de las variaciones en el caudal del río Mendoza como consecuencia de dicho fenómeno (Prieto et al, 1995) ya que coincidirían sus análisis de secuencias de caudales con las consecuencias visibles en el desarrollo y retracción del humedal (figura 7).

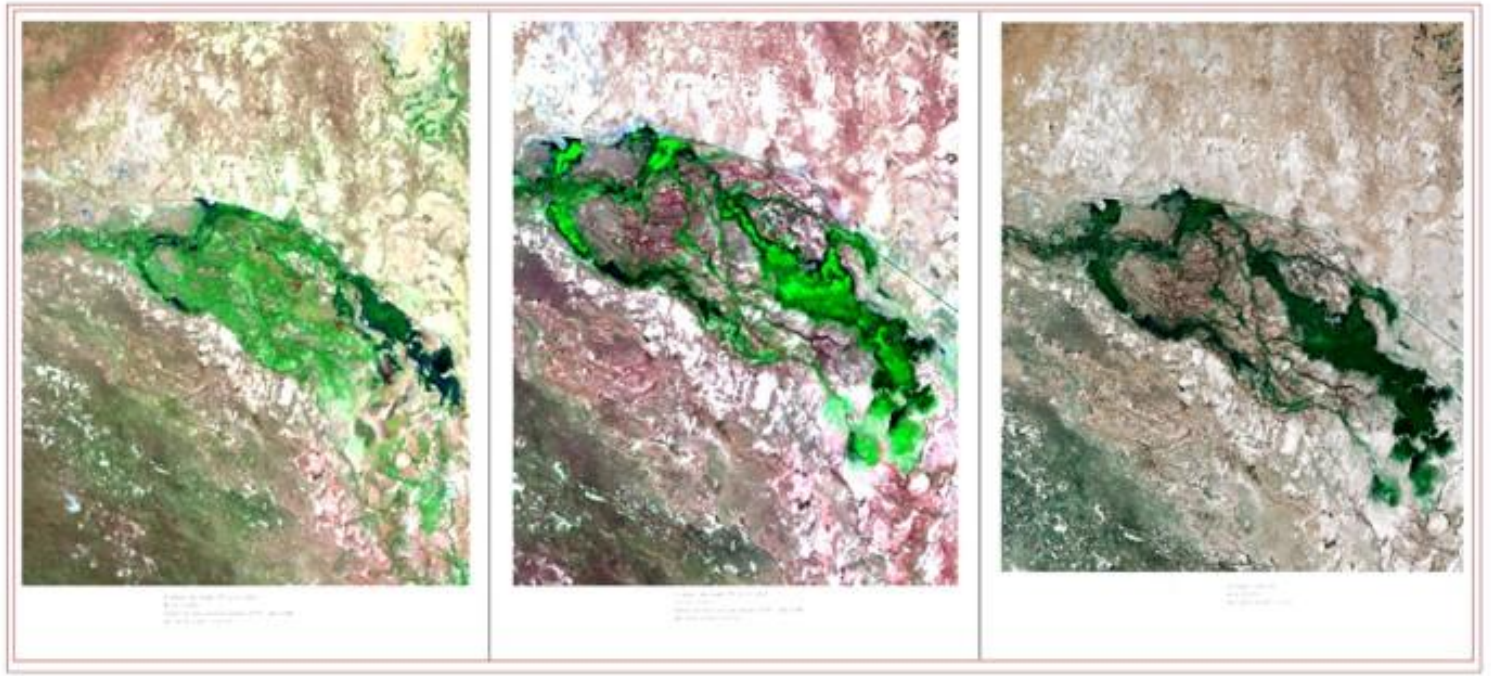

Como ya mencionamos, el Humedal de lagunas de Guanacache sufrió considerables retracciones. En la figura 8 se observa un importante proceso de desecación en la mayoría de las lagunas de este ambiente y el encogimiento de las áreas ocupadas por otras. La secuencia observada en la figura 8 ocurrió en un lapso de 12 años. 

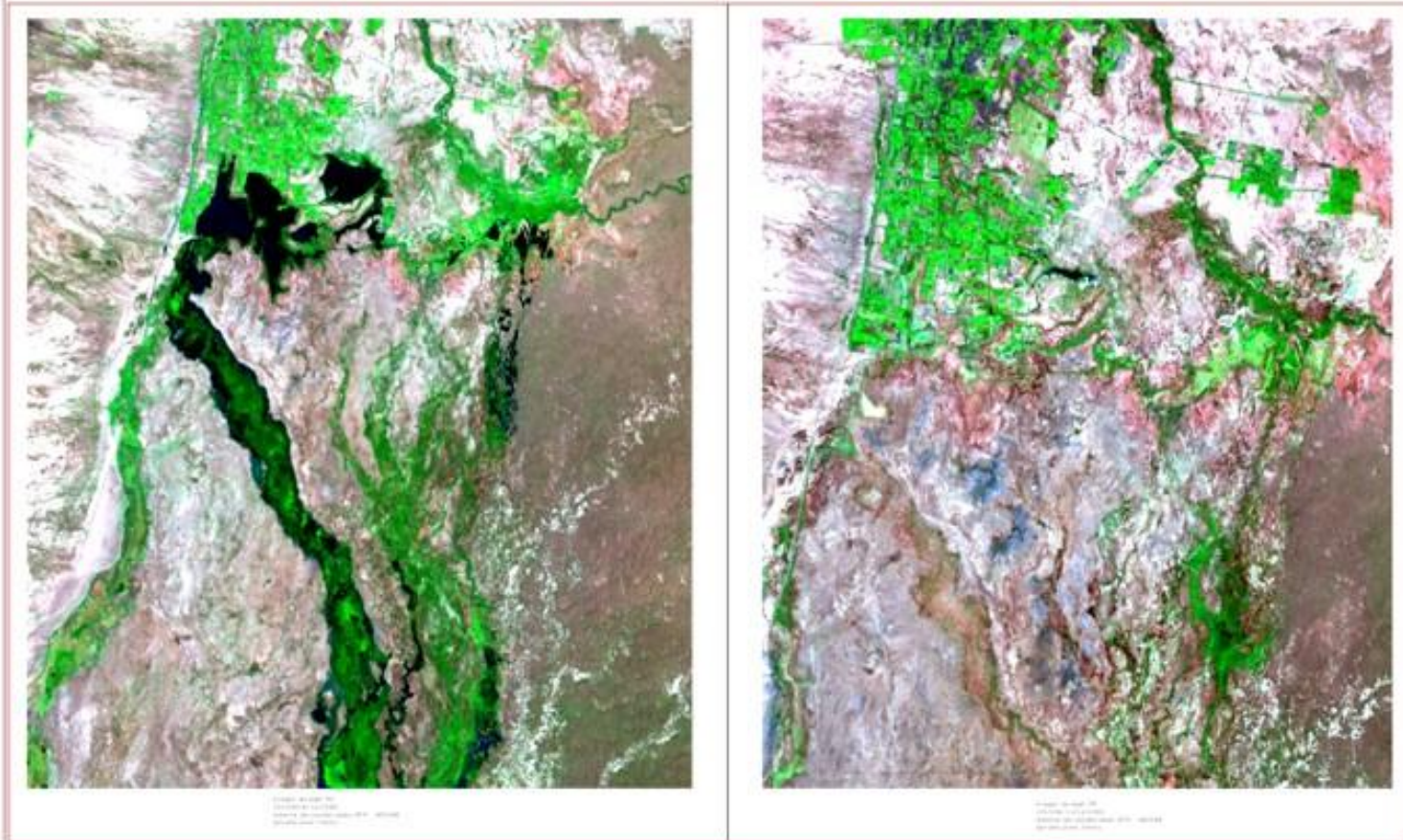

Figura 8. Comparación del Humedal de lagunas de Guanacache en diferentes momentos temporales.

En el caso del Humedal de lagunas y bañados al sur de San Miguel es el que más variaciones sufrió debido a que se observa en las imágenes una desecación total en algunas lagunas y parcial en otras, generando un proceso de desecamiento que no sólo destruye la capacidad fértil del suelo sino que también degrada los recursos del área. En la figura 9 se observa este ambiente en dos momentos temporales diferentes, en 1989, aún con algunas lagunas con agua, pero en el año 2001 no se observan lagunas presentes, ni bañados, sólo el cauce del río Desaguadero. Por el contrario, las áreas que antiguamente estaban ocupadas por lagunas actualmente poseen un suelo infértil, con escasa capacidad para la vida animal y vegetal. 


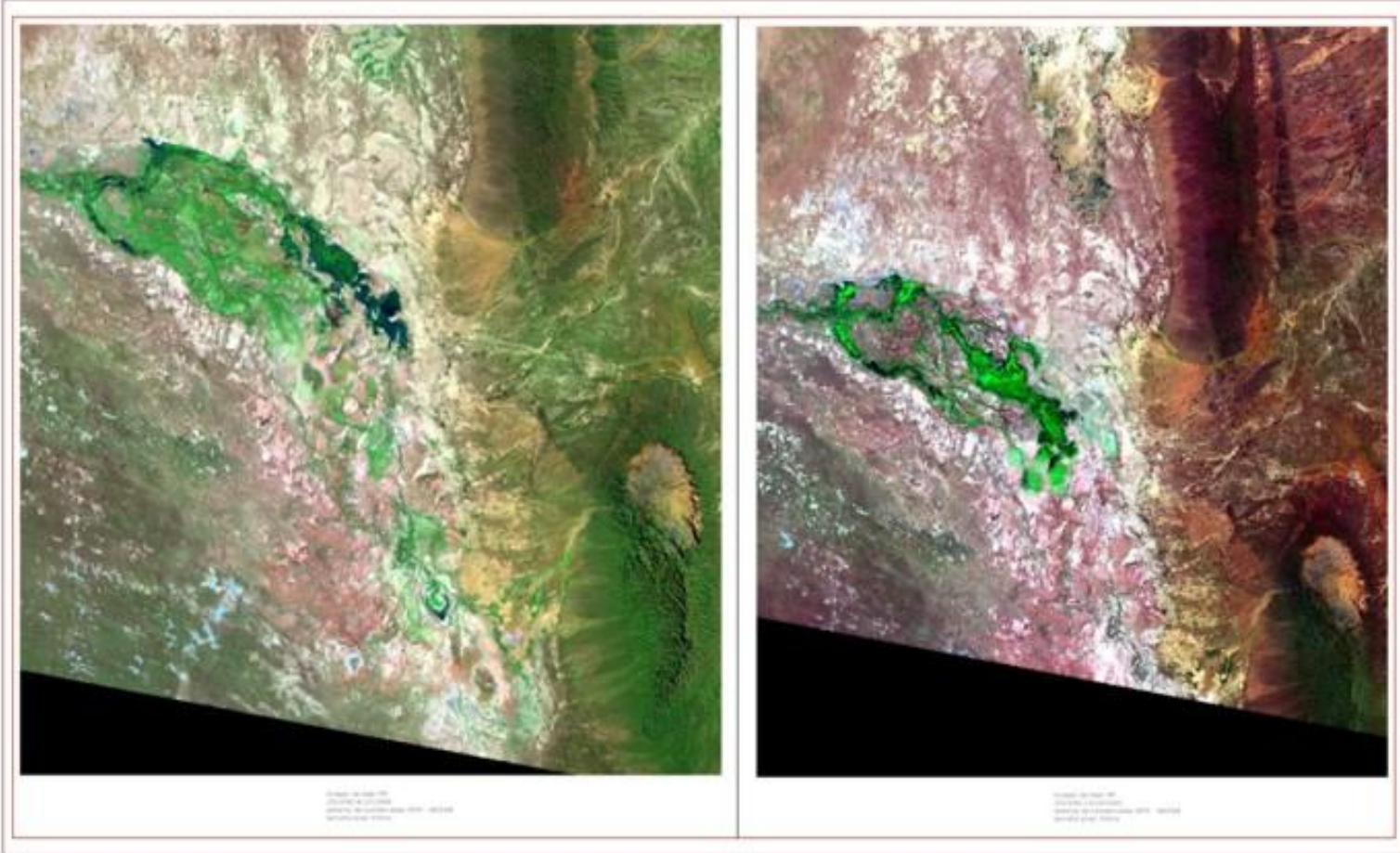

Figura 9. Comparación del humedal de lagunas al sur de San Miguel en diferentes momentos temporales.

\section{CONCLUSIÓN}

El postulado inicial sostiene que la integración de imágenes de diferentes etapas y estaciones con información cartográfica documental histórica, permite reconocer diferencias en las condiciones del ambiente, caracterizar su proceso y definirlo sobre el plano actual del territorio de explotación y los espacios de ocupación humana. De este modo se logra reflejar la dimensión espacial de las relaciones establecidas entre sociedad y entorno natural.

La integración de información de diferente formato integrada por medios tecnológicos permitió definir una marcada variación en la disponibilidad del recurso agua en los últimos 200 años. Esta variación significó el retroceso en las extensiones de algunos humedales y en el desecamiento casi total en otros, aspecto que si bien es claro y notorio, pudo ser mensurado en superficies concretas. A partir de esto, es esperable que las áreas probables de ocupación que históricamente estuvieron vinculadas a la situación que presentaban estas áreas de humedal experimenten cambios al ritmo de su desarrollo o retracción. En ese sentido, es interesante observar que la contracción permanente desde el siglo XVIII en adelante, con situaciones excepcionales de avance puntual, coincide con los procesos de ocupación y reducción poblacional analizados desde estudios arqueológicos y documentales. Los estudios arqueológicos, comparando situaciones ocupacionales entre tierras bajas de humedal, campos de médanos y cauces, tierras intermedias del piedemonte y altas de precordillera, han permitido definir el carácter concentrador de poblaciones que tuvieron los humedales desde los 1600 años AP. 
en las planicies del NE de Mendoza (Chiavazza 2001, 2007, Chiavazza y Prieto 2009, Prieto y Chiavazza 2006). Allí se registraron ocupaciones que tuvieron un carácter interanual a modo de bases residenciales habitadas durante todas las estaciones del año, abocadas a la explotación específica de recursos de humedal, evidente en los registros zooarqueológicos. La pesca tuvo un rol gravitante, no sólo en la economía, sino en los procesos de complejidad que devinieron en modos de integración sociopolítica de cacicazgos entre los huarpes; la que no estuvo atada a sistemas agrícolas tanto como a recursos propios del humedal (Chiavazza 2007).

En tiempos de la temprana colonia (siglos XVI-XVII) estos espacios, aun plenamente desarrollados, sirvieron de refugio a las poblaciones nativas que se resistían al trabajo impuesto por la encomienda (Prieto 2000), dato expuesto por los propios sacerdotes misioneros que la transitaban desde inicios del siglo XVII. De este modo, el noreste provincial se transformó en el reservorio de fuerza de trabajo y recursos que eran demandados en consonancia con el crecimiento del oasis irrigado.

Desde este punto de vista histórico como base a las consideraciones actuales de la Convención Ramsar sobre humedales, como es el reconocimiento de la importancia que poseen estos ambientes de humedal para las comunidades humanas que subsisten a partir del mismo; el análisis del retroceso o desecación en ellos permite entender la afectación no solamente de sobre poblaciones del entorno inmediato, sino que también permite comprender como su afectación incide en la generación de procesos de aridez elevando a una escala más amplia y compleja las consecuencias negativas de dicho proceso.

De acuerdo con los objetivos planteados se confirma el potencial del método analítico aplicado sobre los datos documentales. Esto nos permite verificar que la disponibilidad de mayor cantidad de imágenes que contemplen situaciones estacionales diferenciadas según años de condición climática conocida, la evaluación de correlación entre situaciones ambientales y disponibilidad de recursos permitirá proponer hipótesis referidas al modo de adaptación humana y sus cambios en los patrones de asentamiento.

Próximos estudios que integren datos de aspectos naturales, como las variaciones en las características biogeográficas de la región, y de aspectos humanos, como la distribución histórica y actual de los asentamientos humanos en el sector, analizados mediante las geotecnologías permitirán comprender con mayor profundidad las variaciones en la interrelación experimentada entre ambiente y sociedad en el proceso histórico del norte de Mendoza.

\section{BIBLIOGRAFÍA}

- Abraham, E. y M. R. Prieto. 1981. Enfoque Diacrónico de los Cambios Ecológicos y de las Adaptaciones Humanas en el NE. Árido Mendocino. Cuadernos del CEIFAR 8: 109-139. Mendoza.

- Barros, C; J. Nastri.1995. La perspectiva espacial en Arqueología. Centro Editor de América Latina, Argentina.

- Bosque Sendra J. 1992. Sistemas de Información Geográfica. Ed. Rialp, Madrid. España. 
- Buzai, G. 2005. Sistemas de Información Geográfica en Argentina. Centro de Estudios Avanzados - UBA. (ms versión digital).

- Capel, H. 1998. Una Geografía para el siglo XXI. Scripta Nova, Revista electrónica de Geografía y Ciencias Sociales. № 19. Universidad de Barcelona, España.

- Ceballos García, B. 2002. La Geohistoria, una proposición de análisis de la realidad social contemporánea en los pueblos de América Latina. En: Resúmenes de las IX Jornadas Cuyanas de Geografía. Universidad Nacional de Cuyo. Mendoza.

- Criado Boado, F.1999. Del terreno al espacio: Planteamientos y Perspectivas para la Arqueología del Paisaje. Revista CAPA, $N^{\circ} 6$, Universidad de Santiago de Compostela, España.

- Chiavazza, H. 2001. Las antiguas poblaciones de las arenas. Arqueología en las tierras áridas del NE mendocino. Bienes Patrimoniales, Ediciones Culturales de Mendoza, Mendoza.

- Chiavazza, H. 2007. Cambios ambientales y sistemas de asentamiento en el árido normendocino. Arqueología en los paleocauces del río Mendoza. Tesis Doctoral inédita. Facultad de Ciencias Naturales y Museo. Universidad Nacional de La Plata 1.262 pag.

- Chiavazza, H.; L. Puebla; L. Fiori; C. Ortega y F. Hernández. 2002. Perspectiva Arqueológica territorial; relaciones ciudad desierto desde el estudio de los medanales en Lavalle: el caso de San José. En: Arqueología Histórica Argentina. Actas del Primer Congreso Nacional de Arqueología Argentina. Pp. 89- 110. Ed. Corregidor, Bs As.

- Chiavazza H. y M del R. Prieto. 2009. Estudios arqueológicos en el Río Desaguadero (Mendoza). Runa 29, Instituto de Ciencias Antropológicas, Buenos Aires (en prensa).

- Documento informativo Ramsar № 1. 1998. versión digital en: : http://www.ramsar.org/about/about_infopack_index_s.htm

- González Díaz, E. y L. Fauque. 1993. Geomorfología. XIIo Congreso Geológico Argentino y IIo Congreso de Exploración de Hidrocarburos. Geología y Recursos Naturales de Mendoza. Relatorio I (14), pp.217-234. V.A.Ramos editor.

- Hernández, F. y Chiavazza, H 2008. Aplicaciones Geotecnológicas al estudio arqueológico del NE de Mendoza. En: Revista Geográfica Digital. Instituto de Geografía, Facultad de Humanidades, Universidad Nacional del Nordeste.

- Matteucci, S. D. V. Scheinsohn. 2004. Procesamiento de imágenes, SIG y modelos ecológicos aplicados a la arqueología. Revista GeoFocus, artículo № 4, Pp. 93-109, España.

- Prieto M. del R. 1982. Área del Desaguadero. I Desaguadero del Norte. Programa de investigaciones sobre epidemiología psiquiátrica. Documenta laboris 43 p. CONICET. Bs As.

- Prieto, M. del R. 2000. (1983). Formación y consolidación de una sociedad en un área marginal del Reino de Chile: la Provincia de Cuyo en el siglo XVII. Tesis doctoral, Universidad de Sevilla. Publicada en: Anales del Instituto de Arqueología y Etnología 52-53: 18-366. Facultad de Filosofía y Letras, U.N.Cuyo. Mendoza. 
- Prieto M. y H. Chiavazza. 2006. Ambiente, cultura y relaciones interétnicas en el área huarpe del NE de Mendoza durante el siglo XVIII. En: Jornadas de Ciencia y Técnica Sección poster. UNCuyo. Mendoza.

- Prieto, M.R., R. Herrera y P. Dussel. 1995. Evidencias históricas de fluctuaciones climáticas en la cordillera de los Andes a partir del estudio diacrónico del caudal del río Mendoza (s.XVII al XX). Facultad de Filosofía y Letras, Universidad Nacional de Cuyo, Mendoza.(informe inédito presentado a la SECyT, UNCuyo).

- Regairaz y Barrera, 1975. Formaciones del cuaternario. Unidades Geomorfológicas y su relación con el escurrimiento de las aguas en el piedemonte de la Precordillera, Anales de la Academia Brasileña de ciencias, 47: 5-26.

- Roig, F.; A.Roig, M.Roig,V.Roig y E. Roig. 1999. Guanacache. Fidel Roig Matons, pintor del Desierto. Ediunc. Mendoza.

- Rusconi, C. 1962. Poblaciones Pre y post hispánicas de Mendoza. Volumen III "Arqueología". Edición Oficial, Mendoza.

- Triviño, L. 1977. Antropología del Desierto. Fundación para la Educación, la Ciencia y la Cultura. Buenos Aires.

- Vagaggini, V, G. Dematteis. 1977. El método analítico de la Geografía. En: Revista TERRA, № 1, Universidad Central de Venezuela. Venezuela.

- Vignati M. 1953. Un diario del Viaje por las Lagunas de Guanacache en el año 1789. Aportes al conocimiento Antropológico de la Provincia de Mendoza. Cap. III. Notas del Museo Eva Perón, XVI, 58-61:51-109. La Plata. 